NASA/TM-2002-211985

AIAA-2003-1089

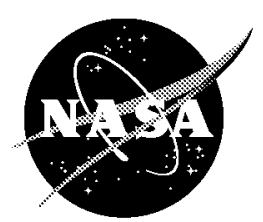

Setting up a Rayleigh Scattering Based Flow Measuring System in a Large Nozzle Testing Facility

Jayanta Panda

Ohio Aerospace Institute, Brook Park, Ohio

Carlos R. Gomez

Glenn Research Center, Cleveland, Ohio 
The NASA STI Program Office ... in Profile

Since its founding, NASA has been dedicated to the advancement of aeronautics and space science. The NASA Scientific and Technical Information (STI) Program Office plays a key part in helping NASA maintain this important role.

The NASA STI Program Office is operated by Langley Research Center, the Lead Center for NASA's scientific and technical information. The NASA STI Program Office provides access to the NASA STI Database, the largest collection of aeronautical and space science STI in the world. The Program Office is also NASA's institutional mechanism for disseminating the results of its research and development activities. These results are published by NASA in the NASA STI Report Series, which includes the following report types:

- TECHNICAL PUBLICATION. Reports of completed research or a major significant phase of research that present the results of NASA programs and include extensive data or theoretical analysis. Includes compilations of significant scientific and technical data and information deemed to be of continuing reference value. NASA's counterpart of peerreviewed formal professional papers but has less stringent limitations on manuscript length and extent of graphic presentations.

- TECHNICAL MEMORANDUM. Scientific and technical findings that are preliminary or of specialized interest, e.g., quick release reports, working papers, and bibliographies that contain minimal annotation. Does not contain extensive analysis.

- CONTRACTOR REPORT. Scientific and technical findings by NASA-sponsored contractors and grantees.
- CONFERENCE PUBLICATION. Collected papers from scientific and technical conferences, symposia, seminars, or other meetings sponsored or cosponsored by NASA.

- SPECIAL PUBLICATION. Scientific, technical, or historical information from NASA programs, projects, and missions, often concerned with subjects having substantial public interest.

- TECHNICAL TRANSLATION. Englishlanguage translations of foreign scientific and technical material pertinent to NASA's mission.

Specialized services that complement the STI Program Office's diverse offerings include creating custom thesauri, building customized databases, organizing and publishing research results ... even providing videos.

For more information about the NASA STI Program Office, see the following:

- Access the NASA STI Program Home Page at http://www.sti.nasa.gov

- E-mail your question via the Internet to help@sti.nasa.gov

- Fax your question to the NASA Access Help Desk at 301-621-0134

- Telephone the NASA Access Help Desk at 301-621-0390

- Write to: NASA Access Help Desk NASA Center for AeroSpace Information 7121 Standard Drive Hanover, MD 21076 


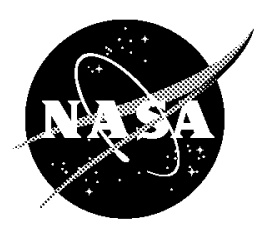

\section{Setting up a Rayleigh Scattering Based Flow Measuring System in a Large Nozzle Testing Facility}

Jayanta Panda

Ohio Aerospace Institute, Brook Park, Ohio

Carlos R. Gomez

Glenn Research Center, Cleveland, Ohio

Prepared for the

41st Aerospace Sciences Meeting and Exhibit

sponsored by the American Institute of Aeronautics and Astronautics

Reno, Nevada, January 6-9, 2003

National Aeronautics and

Space Administration

Glenn Research Center 


\section{Acknowledgments}

The authors acknowledge useful advice from Dr. Richard G. Seasholtz, NASA Glenn Research Center, and help in Labview programming from Kristie A. Elam, Akima Corporation.

The Aerospace Propulsion and Power Program at NASA Glenn Research Center sponsored this work.

Available from

NASA Center for Aerospace Information 7121 Standard Drive

Hanover, MD 21076
National Technical Information Service 5285 Port Royal Road Springfield, VA 22100

Available electronically at http://gltrs.grc.nasa.gov 


\title{
Setting up a Rayleigh Scattering Based Flow Measuring System in a Large Nozzle Testing Facility
}

\author{
Jayanta Panda* \\ Ohio Aerospace Institute \\ Brook Park, Ohio 44142 \\ Carlos R. Gomez \\ National Aeronautics and Space Administration \\ Glenn Research Center \\ Cleveland, Ohio 44135
}

\begin{abstract}
A molecular Rayleigh scattering based air density measurement system has been built in a large nozzle testing facility at NASA Glenn Research Center. The technique depends on the light scattering by gas molecules present in air; no artificial seeding is required. Light from a single mode, continuous wave laser was transmitted to the nozzle facility by optical fiber, and light scattered by gas molecules, at various points along the laser beam, is collected and measured by photon-counting electronics. By placing the laser beam and collection optics on synchronized traversing units, the point measurement technique is made effective for surveying density variation over a cross-section of the nozzle plume. Various difficulties associated with dust particles, stray light, high noise level and vibration are discussed. Finally a limited amount of data from an underexpanded jet are presented and compared with expected variations to validate the technique.
\end{abstract}

\section{INTRODUCTION}

Typically, large testing facilities in various industrial and government facilities, involving high speed flow, have limited options for instrumentations to measure flow parameters such as velocity, temperature, and density. Flow information is usually inferred from schlieren visualization. Despite the desire to use Computational Fluid Dynamics (CFD) simulations, validation of the codes is again hampered due to a lack of quantitative experimental data. The present work is a part of an ongoing effort to develop the
Rayleigh scattering based technique to provide benchmark data. In principle, a single measurement of Rayleigh spectrum provides a measure of density, temperature, and one component of velocity by non-intrusive means.

The lack of aerodynamic data from full scale or large scale model testing is primarily due to the problems in using the traditional experimental tools which either are too intrusive or uses seed particles. Mounting intrusive probes, such as a rake of pitottubes or thermocouples in high-speed, high temperature flows is not always easy due to structural and vibration issues. Frequently the probe and the mount can cause undesirable alteration of the flow. Hot-wire anemometry, a universal laboratory tool, is hardly used for similar reasons. Recent advancement of non-intrusive laser based techniques is promising; however, commercially available Laser-Doppler Velocimetry (LDV) and Particle Image Velocimetry (PIV) require the use of seed particles which bring a new set of problems. Seeding a large volume of flow can be challenging, seed particles contaminate facility and coat models and windows, and often time the particles are abrasive. In addition, there are measurement uncertainties from various biasing errors in turbulent flows, problems associated with seed particles passing through shock waves, and beam steering effects from sharp density gradients. The Rayleigh scattering technique, on the other hand, depends on the light scattering from air molecules. Since, no seed particles are used and only a single beam is necessary, many problems associated with

${ }^{*}$ Senior member, AIAA 
LDV and PIV can be overcome. Moreover, information is obtained directly from the molecular distributions; therefore, the Rayleigh scattering technique is a more fundamental way of measuring flow properties. ${ }^{1}$ Implementation of this technique, however, requires some special attention to issues such as cleanliness of air, suppression of background light etc., which are discussed in this paper.

In the past, a number of Rayleigh scattering based optical flow diagnostic techniques have been developed. Since the Rayleigh scattering crosssection is different for different gas molecules, mixing between two different species can be measured from a variation of scattering intensities. ${ }^{2}$ For a fixed composition gas mixture, such as air, the Rayleigh scattering technique has been used to measure velocity, temperature, and density over an $\operatorname{area}^{3,4}$ or at a point. ${ }^{5-8}$ The former uses a tunable laser and molecular absorption filters, such as the hyperfine absorption lines of Iodine vapors, and has the obvious advantage of data collection from a large number of points. The latter uses continuous wave laser and high-resolution optical spectrum analyzer, such as a Fabry-Perot interferometer, and has the advantage of accuracy and ability to measure unsteady turbulent statistics of density and velocity fluctuations. ${ }^{7,8}$ The present work follows the second methodology, which perhaps is better suited for larger facility that may require light transmission through optical fibers.

Rayleigh scattering Principles: When a laser beam is allowed to pass through a gas, the molecules present in the gas cause inelastic and elastic light scattering. The inelastic part is called Raman scattering and the elastic part as Rayleigh scattering. The Raman scattering cross-section is substantially weaker than that of Rayleigh scattering; typically for Nitrogen at room temperature vibrational and rotational Raman scattering contribute 0.1 and 1 percent of the total scattered light ${ }^{1}$ respectively. Therefore, the elastic Rayleigh scattering process describes most of the scattered light. For gas density measurement, variation of the total light intensity with the molecular number density is of interest. Since this variation is identical for both Rayleigh and Raman scattering process, a separation between the two is unnecessary. The current setup was used to measure air density only. However, the following surmises principles to measure all three quantities: density, temperature, and a component of velocity.

A simplistic description of the measurement process, using optical spectrum analysis of Rayleigh scattered light is schematically shown in Fig. 1(a). Since the Doppler shift frequency is of the order of a few Gigahertz, a narrow line width (of the order of $10 \mathrm{MHz}$ ) incident laser beam is necessary to resolve the Rayleigh spectrum. In the case of a moving gas media, the bulk motion is superimposed on the random velocity of the individual molecules; therefore shift between the peaks of the incident laser line and the Rayleigh spectrum provides a measure of the bulk velocity. The Full Width at Half Maxima (FWHM) depends on the spread of molecular motion and, therefore, is a measure of gas temperature. Finally, the total light under the Rayleigh spectrum is proportional to the molecular number density and provides a measure of gas density.

Figure 1(b) presents a scattering diagram, where $\mathbf{K}_{\mathrm{i}}$ is the incident wave vector, $\mathbf{K}_{\mathrm{s}}$ is the scattered wave vector pointing towards the collection optics and, $\mathbf{K}=\mathbf{K}_{\mathrm{s}}-\mathbf{K}_{\mathrm{i}}$, is the scattering vector. For $\left|\mathbf{K}_{\mathrm{s}}\right|$ $\approx\left|\mathbf{K}_{\mathrm{i}}\right|$, the magnitude of the scattering vector becomes $K=2 K_{i} \sin \left(\theta_{s} / 2\right)$, and the Doppler shift from the bulk velocity $\mathrm{U}$ of the flow is

$$
\mathrm{f}_{\mathrm{d}}=\frac{\mathbf{K} \cdot \mathbf{U}}{2 \pi}=\frac{2 \mathrm{U} \cos \Phi \sin \left(\frac{\theta_{\mathrm{s}}}{2}\right)}{\lambda_{\mathrm{i}}}
$$

where, $\Phi$ is the angle between the scattering vector $\mathbf{K}$ and the velocity vector $\mathbf{U}$, and $\lambda_{\mathrm{i}}$ is the wavelength of the incident light. The measured component of velocity is $V_{r}=U \cos \phi$. The same Doppler shift principle applies to the individual molecules as well. If the gas molecules are assumed to have a Maxwellian velocity distribution and if Brillouin scattering is assumed to be negligible then the bandwidth (Full Width at Half Maxima) of Rayleigh spectrum becomes 

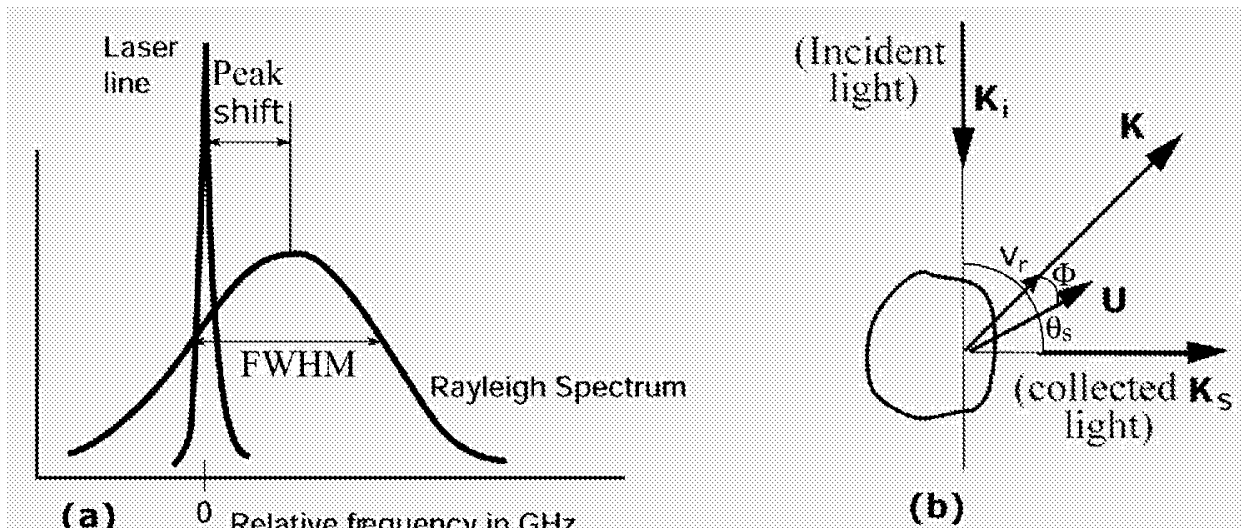

(a) 0 Relative frequency in $\mathrm{GHz}$

(b)

Figure 1. (a) Schematic to explain velocity, temperature and density measurement from Rayleigh Spectrum; (b) Scattering diagram.

$$
\Delta \mathrm{f}=0.265 \mathrm{~K}\left(\frac{2 \mathrm{kB}_{\mathrm{B}} \mathrm{T}}{\mathrm{m}}\right)^{1 / 2}
$$

where, $\mathrm{k}_{\mathrm{B}}$ is the Boltzmann's constant, $\mathrm{m}$ is molecular mass and $\mathrm{T}$ is gas temperature. Clearly, for a fixed optical setup (K fixed) and a given gas mixture (m fixed) the bandwidth of Rayleigh spectrum is proportional to the square root of temperature.

The density of the gas/gas-mixture is proportional to the area under the spectrum. Therefore, to measure density alone no optical spectrum analysis is required; a measure of total scatter light is sufficient. The intensity of total scattered light $\mathrm{P}_{\mathrm{s}}$ collected from a probe volume, $\mathrm{V}_{\mathrm{sc}}$ into a solid angle, $d \Omega$, can be written as:

$$
\mathrm{P}_{\mathrm{S}}=\mathrm{nI}_{0} \mathrm{~V}_{\mathrm{Sc}} \frac{\mathrm{d} \sigma}{\mathrm{d} \Omega} \sin ^{2} \chi \mathrm{d} \Omega=\mathrm{k}^{\prime} \mathbf{n} .
$$

Here $\mathbf{n}$ is the molecular number density, $\mathrm{I}_{0}$ is the incident light intensity, $\mathrm{d} \sigma / \mathrm{d} \Omega$ is the differential Rayleigh scattering cross-section of the gas (or gas mixture) under consideration, $\chi$ is the angle between the incident electric vector and the direction of light collection, and $\mathrm{k}^{\prime}$ is a constant. The Rayleigh scattering cross-section depends on the light wavelength and the effective molecular diameter. This is constant for a fixed wavelength laser and a fixed gas mixture (air for this work). For a fixed optical setup, the scattered laser power is directly proportional to the molecular number density, which in turn is directly related to the bulk density, $\rho$. Therefore,

$$
P_{s}=k^{\prime \prime} \rho
$$

where $\mathrm{k}^{\prime \prime}$ is a constant. Now the scattered light intensity was measured using a photomultiplier tube and a photon counting process was used. The number of photons $\mathrm{N}$ collected during a fixed time interval $\Delta t$ can be written as:

$$
\mathrm{N}=\frac{\varepsilon \mathrm{P}_{\mathrm{S}} \Delta \mathrm{t}}{\mathrm{h} v}=\mathrm{k} \rho \Delta \mathrm{t}
$$

where, $h$ is the Planck constant, $v$ is the frequency of the laser light and $\varepsilon$ is the overall collection efficiency (a product of the light transmission efficiency and the quantum efficiency of the photomultiplier tube). Equation 5 shows that the photon count over a fixed time interval is directly proportional to the gas density at the probe volume. The proportionality constant $\mathrm{k}$ has to be determined through a calibration process. Typically, the overall collection efficiency was about 5 percent. 


\section{EXPERIMENTAL SET UP}

The measurement system was setup in an advanced nozzle and engine component test facility ${ }^{9}$ in the Engine Research Building of the NASA Glenn Research Center. A schematic of the facility is shown in Fig. 2. The nozzle itself is enclosed in a large stainless steel tank of 7.5 feet diameter and 23 feet length. The tank is split into a fixed and a movable part; the latter is retracted downstream to allow access to the model. When closed, an inflatable rubber seal prevents leakage through the joint. Static pressure below ambient value is maintained in the tank to simulate various high altitude engine operations. Two different compressed air lines supply the model, and the tank is connected to a vacuum (altitude exhaust) system. All of these air lines come from a centrally located supply that provides for all the facilities in the center. The primary compressed air is a 40 psi $(276 \mathrm{kPa})$ supply that can deliver up to $40 \mathrm{lb} / \mathrm{s}(18 \mathrm{~kg} / \mathrm{s})$ of continuous unheated flow or $30 \mathrm{lb} / \mathrm{s}(13.6 \mathrm{~kg} / \mathrm{s})$ of heated $\left(370^{\circ} \mathrm{F} \max \right)$ flow. The secondary compressed air is a 450 psi
(3.1 MPa) supply that can deliver unheated air at a maximum rate of $8 \mathrm{lb} / \mathrm{s}(3.6 \mathrm{~kg} / \mathrm{s})$.

The optical access to the facility is through a pair of 23 inch $(0.584 \mathrm{~m})$ diameter schlieren windows. The nozzle was installed such that upon closing the tank, the upstream edges of schlieren windows lined up with the nozzle lip. There is a flow collector 21 inch $(0.533 \mathrm{~m})$ downstream of the nozzle lip. Therefore, a limited extent of the plume, bounded by the diameter of the schlieren windows and the location of flow collector is measurable in this facility.

The present paper reports a limited amount of data collected from a convergent, $20 \mathrm{in}^{2}{ }^{2}$ exit area (5.046 inch or $0.128 \mathrm{~m}$ diameter), circular geometry nozzle that was supplied by the primary 40 psi $(276 \mathrm{kPa})$ compressed air supply. The nozzle was operated in under-expanded condition at Nozzle Pressure Ratio $=10\left(\mathrm{P}_{0}=18.2 \mathrm{psi}\right.$ or $125.6 \mathrm{kPa}, \mathrm{T}_{0}=540 \mathrm{R}$ or $300 \mathrm{~K}$ ).

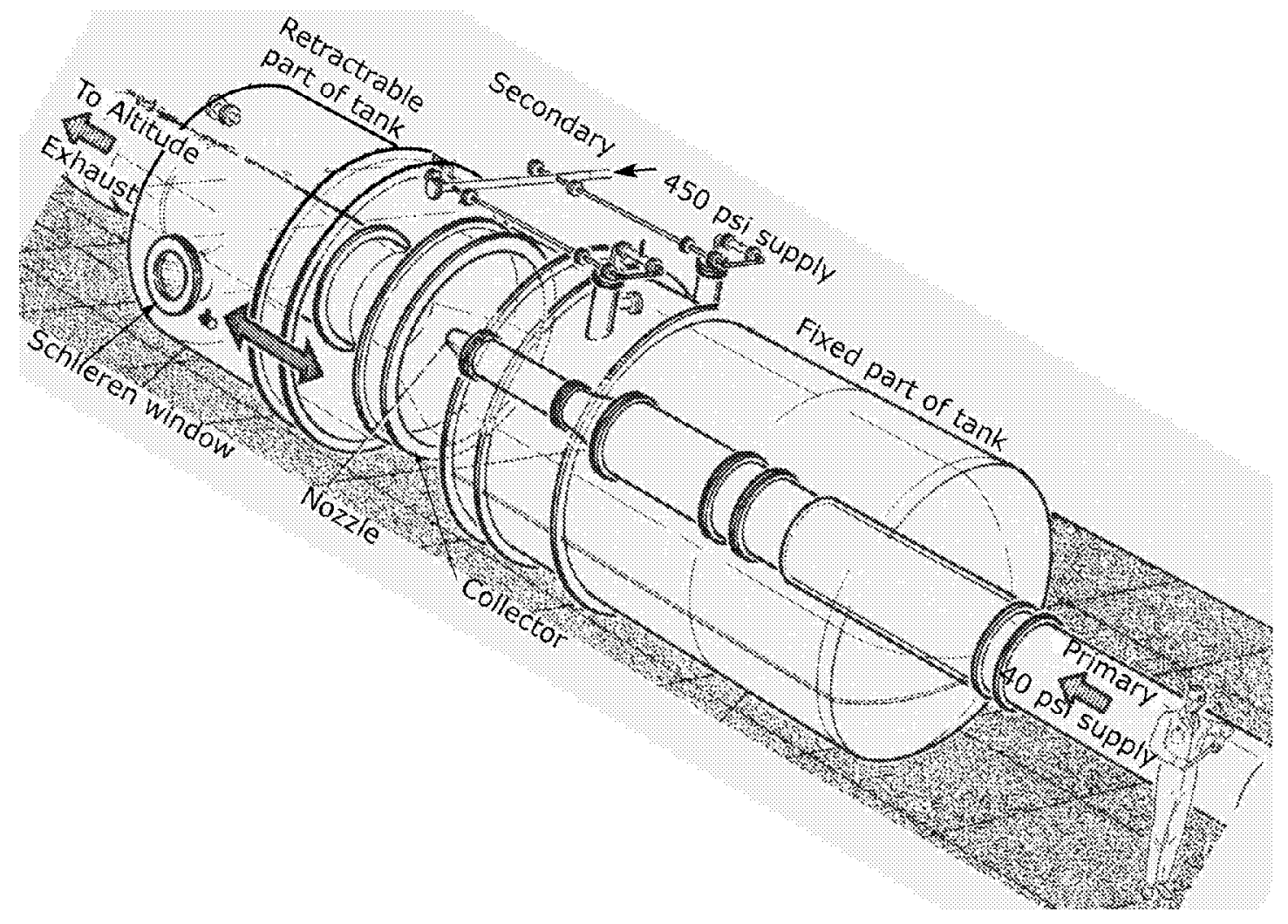

Figure 2. Sketch of the advanced nozzle and engine component test facility. 
Figures 3 and 4 show a sketch and a photograph of the optical arrangement respectively. The photograph was taken with the movable part of the tank retracted downstream. The schlieren windows are positioned farther left and are not visible in the photograph. The sketch, on the other hand, shows the final setup with tank closed. Green laser light at $532 \mathrm{~nm}$ wavelength from a solid state, frequency doubled, single mode, $\mathrm{Nd}: \mathrm{VO}_{4}$ Laser was transmitted inside the enclosing tank via a single mode, polarization maintaining optical fiber. Although the laser is capable of producing 5 watts of power, the capacity of the 4 micron core diameter, pure silica, optical fiber limited the available light in the tank to 400 milliWatts only. The transmitted part of the beam was collimated and deflected downward to be at the center plane of the nozzle plume. The beam ultimately dissipated in a long beam dump that was laid parallel to the flow direction. The transmission optics in the tank also included a laser power meter, which monitored the transmitted laser power and was helpful in coupling the laser beam to the optical fiber. The polarization plane of the laser beam was adjusted for the peak scattering orientation to line up towards the collection optics.

Light scattered by air molecules from the laser beam was collected through one of the schlieren windows by a $150 \mathrm{~mm}$ diameter $\mathrm{f} / 10$ achromat, depicted as L1 in Fig. 3, placed outside the tank. Another $150 \mathrm{~mm}$ diameter $\mathrm{f} / 3$ achromat, depicted as L2 in Fig. 3, focused the collected light on a $0.9 \mathrm{~mm}$ high and $0.4 \mathrm{~mm}$ wide slit. Light passing through the slit was focused on the cathode surface of a photomultiplier tube (PMT). The height of the slit and the imaging ratio of the collection optics fixed the probe volume length to $3 \mathrm{~mm}$. The transmission beam diameter was about $1 \mathrm{~mm}$; the slit width was sufficient to allow light scattered from entire beam diameter to reach PMT. The collection assembly was mounted on an $X-Y$ traverse while the transmission optics inside the tank was mounted on a single X-traverse. The combination allowed survey of the jet plume over a longitudinal plane. The X-traversing units were synchronized to move along axial direction, while the Y-traversing unit allowed light to be collected from various vertical positions on the beam.
The success of a Rayleigh scattering system is dependant on close attention to some additional details such as, removal of dust particles from air flow, attenuation of stray scattered light and separation of sensitive optical components from vibration and noise sources. The dry compressed air from the central facility was passed through additional filters, situated inside the test cell, before arriving at the model. An examination of residues in these existing filter housings showed that the $40 \mathrm{psi}$ air was contaminated by some amount of desiccant particles and the $450 \mathrm{psi}$ line by fine rust from an old header. The supply lines from the filter hosing to the model were made of stainless steel, the interior of which did not rust, but the $450 \mathrm{psi}$ line had a thin coating from rust particles that escaped the existing coarse filters. An acceptable solution was obtained by using fine filters that removed 99.8 percent of all particles above 0.3 micron size in both the airlines. Large surface area of the filters ensured small pressure drop across the filter housing. The existing rust particles from $450 \mathrm{psi}$ line were purged by allowing the maximum air flow (with the fine filer in place) for a couple of hours. A time signature of PMT current provides an easy check on the cleanliness. Since particle (Mie) scattering is a few orders of magnitude stronger than the Rayleigh scattered light, passage of most dust particles lead to a sharp rise in PMT current. Nevertheless, a few particles-in the present experiment about 100/sec. - are deemed tolerable for time averaged density measurement. In an open jet facility, one needs to provide clean dust free air for the entrained flow as well. ${ }^{7,8}$ The large enclosure tank, in spite of a source of many other difficulties, eliminated this problem, as the trapped air inside the tank was quickly replaced by clean supply air within a couple of minutes of operation.

To reduce background light level, the beam dump was designed to minimize back scattering and various baffles were placed around optical components inside the tank. The second schlieren window was covered by black cloth to provide a dark background. All windows in the test cell were covered and all lights inside the test cell were turned off. The facility itself was operated remotely from an adjoining control room. All other aspects of the Rayleigh scattering experiment were also controlled from this room. 


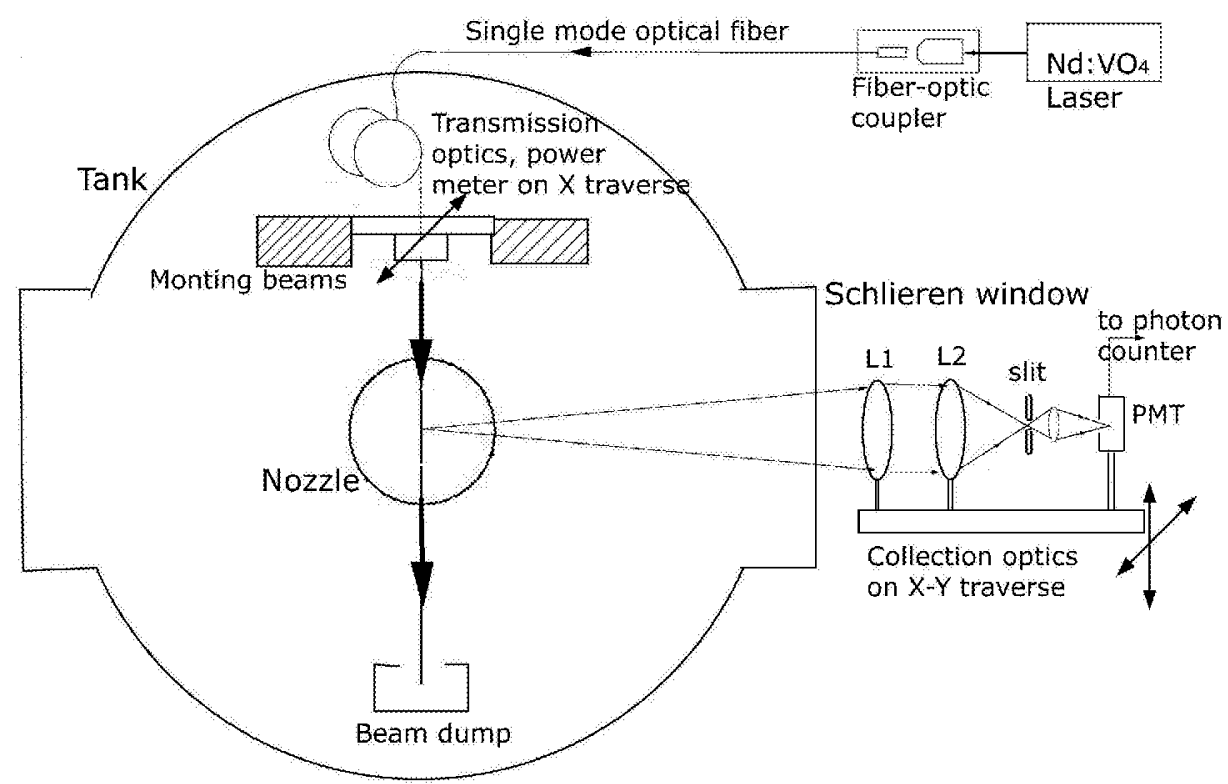

Figure 3. Schematic of the optical setup.

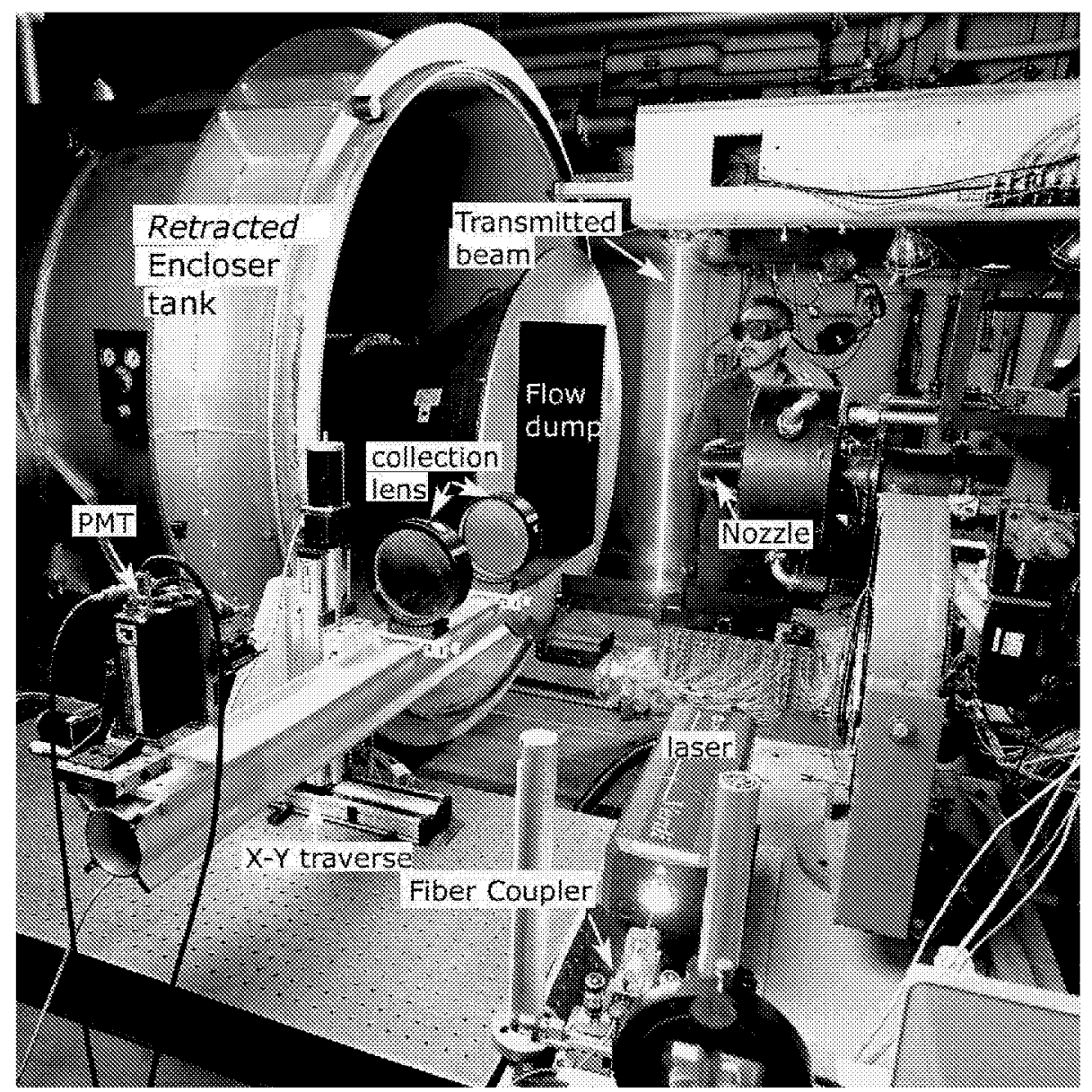

Figure 4. Photograph of the optical arrangement. The enclosing tank was retracted downstream. 
The fiber-based light transmission system was mostly successful to separate the laser source from the high level of facility vibration. However, the mechanical mounting and positioning units for coupling laser light to the optical fiber was found to be sensitive to facility vibration. The core diameter of the single mode fiber was 4 micro-meter and small vibration easily affected coupling efficiency, which resulted into some unsteadiness in the laser light transmitted inside the tank. The Rayleigh scattering technique can be used to measure density variations associated with turbulent fluctuations in the plume, ${ }^{7,8}$ however, since the incident light itself fluctuated, such measurements were impossible in the present setup. The time-averaged measurements were not affected as the power meter provided a measure of average transmitted power. In the present setup the fiber coupler was placed in the same test cell with the facility, and therefore, was subjected to a relatively high level of vibration and noise. In future, the laser and the coupling arrangement will be placed in the adjoining control room to avoid this problem.

Data acquisition and processing: The low level of the scattered light called for a photoelectron counting system. A counter that provided counts over a series of 16384 contiguous bins of specified time duration was used. The passage of stray particles was identified and the specific time bins were rejected through software based postprocessing that rejected data points beyond 5 times the standard deviation. Note that such a software-based technique cannot remove excess counts from small particles moving at a faster speed or weaker signatures from particles passing through the edges of the beam. The photoelectron counter and all traversing units were controlled remotely. So was the monitoring for facility pressure and temperature probes, mass flow devices and transmitted laser power.

Alignment of the collection optics, so that the image of the beam is centered at the slit at all axial and radial locations, became an important issue (fig. 3). The transmission optics inside the tank and the collection optics outside were placed on separate traverses. Various factors, such as thermal contractions from progressive cooling of the tank, small irregularities in the schlieren window and small error in alignment caused the image of the probe volume from various parts of the laser beam to drift outside the slit aperture. To mitigate this problem, the slit was centered at every measurement point by surveying the change in photoelectron count while the collection optics is moved axially by very small increments. The axial position that provided peak count corresponded to the best alignment. Such surveys were performed before acquiring data from any measurement point.

\section{RESULTS}

Time-averaged density data were measured via photon counting over a $5.4 \mathrm{sec}$ interval. A calibration process is necessary to determine the proportionality constant between the rate of photon count $\mathrm{N}$, and the air density $\rho$; as well as to determine the residual stray light collected through the optics. Plumes at various known density conditions were easily obtained by changing both the supply pressure $\mathrm{P}_{0}$ and tank pressure $\mathrm{P}_{\mathrm{t}}$. The air density at the plume core can be determined from isentropic relation till a choked condition, NPR $\leq 1.89$, is reached:

$$
\rho=\frac{\mathrm{P}_{0}}{\mathrm{R}_{\mathrm{T}}}\left(\frac{\mathrm{P}_{0}}{\mathrm{P}_{\mathrm{t}}}\right)^{-\frac{1}{\gamma}}
$$

where, $T_{0}$ is the total temperature of supplied compressed air, $\mathrm{R}$ is the universal gas constant, and $\gamma$ is the ratio of specific heats. The photon arrival rate was counted at different operating conditions and a straight line,

$$
\mathrm{N}=(\mathrm{a} \rho+\mathrm{b}) \Delta \mathrm{t}
$$

was fitted through the data (fig. 5) using the leastsquares method. The slope of the line provided the proportionality constant as shown in equation 5 , and the intercept provided a measure of the stray light. It should be pointed out that the density variations, encountered in the underexpanded jet plumes, occur over a wider range than the range used for calibration. However, the calibration is expected to remain valid over the entire range due to the fundamental linear relationship between the molecular number density and the intensity of scattered light. 


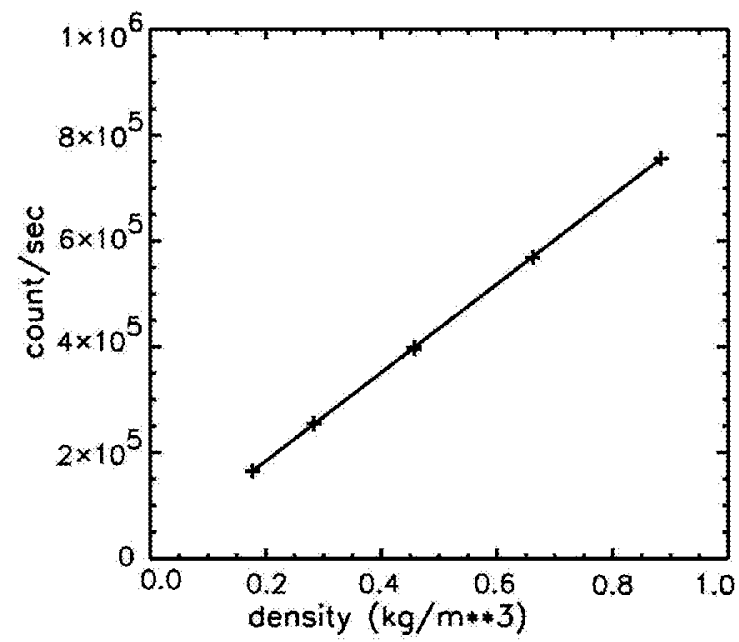

Figure 5. Air density versus photoelectron count calibration.

The fundamental error source in the time-averaged measurements arises from the electronic shot noise that manifests as the statistical photon count noise. The shot noise is proportional to the variance of the number of photons $(\mathrm{N})$ detected over a fixed time interval in repeated measurements. Since the detection of photons obeys Poisson's statistics, variance of the photon count is equal to the average number of counts, i.e., $\sigma_{\mathrm{N}}=\mathrm{N}$. As a result the relative uncertainty in the measurement of $\mathrm{N}$ is given by

$$
\frac{\sigma_{N}^{1 / 2}}{N}=N^{-1 / 2}
$$

For the present experiment the count rate was high; over a 5.4 second interval the number counted was between 1 to 5 million. Therefore, the uncertainty from the shot noise was below 0.1 percent. Since, the contribution from the fundamental noise source was very low, that from a host of secondary sources became prominent. Occasional particles were unavoidable and their passage led to an increase in the photon count. As mentioned earlier, vibration from the facility caused unsteadiness in the transmitted laser power. Finally, alignment between the slit in the collection optics and the laser beam inside the tank brought additional random uncertainty in density measurement. These secondary noise sources are difficult to quantify. It is expected that some of the sources lead to bias error and the others to random error (precision error). The calibration of photon arrival rate against known density values is expected to account for some of the bias error. The random part of the uncertainty was estimated to be about \pm 5 percent of the reported value. Usually, a calibration curve was obtained at the beginning or at the end of a day, and was used for all data acquired in that day.

Figure 6(a) shows a density survey along the centerline of an underexpanded $\left(\mathrm{NPR}=10, \mathrm{P}_{0}=\right.$ $18.2 \mathrm{psi}, \mathrm{T}_{0}=540 \mathrm{R}$ ) plume from a convergent nozzle. Air density progressively fell as the flow expanded till a Mach disk is formed at $\mathrm{x} / \mathrm{D}=2.1$. Subsequently, there occurs a sudden jump, as expected across a normal shock. The flow field immediately downstream of the choked nozzle, and bounded downstream by the Mach disk and radially by an incident shock originating from the nozzle lip, ${ }^{10}$ is driven by isentropic expansion. The variations of flow Mach number and thermodynamic parameters can be easily predicted numerically through the Method of Characteristics. Owen and Thornhill ${ }^{11}$ presented one such calculation. For the present work a slightly different scheme outlined by Shapiro ${ }^{12}$ was used. An excellent agreement between the measured density variation and the numerically calculated values goes towards the validation of density measurement technique. Figure 6(b) shows a radial profile obtained close to the nozzle exit. The cold plume had a higher density than the ambient. The shear layer and incident shock around the plume periphery created the sharp density gradient leading to the jet core.

\section{CONCLUDING COMMENTS}

One of the strengths of Rayleigh scattering based technique is the ability to simultaneously obtain information about flow density, temperature, and a component of velocity from a single measurement. The last two require spectral analysis of the collected light while the first does not. Therefore density measurement serves as a first step towards the realization of the technique's full potential. The basic requirements, such as the cleanliness of the airflow, suppression of background light and effective vibration isolation, have been reasonably fulfilled in the current setup. It is hoped that in future entries the remaining problem with vibration will be properly addressed and the optical setup will be expanded to measure temperature and velocity. 

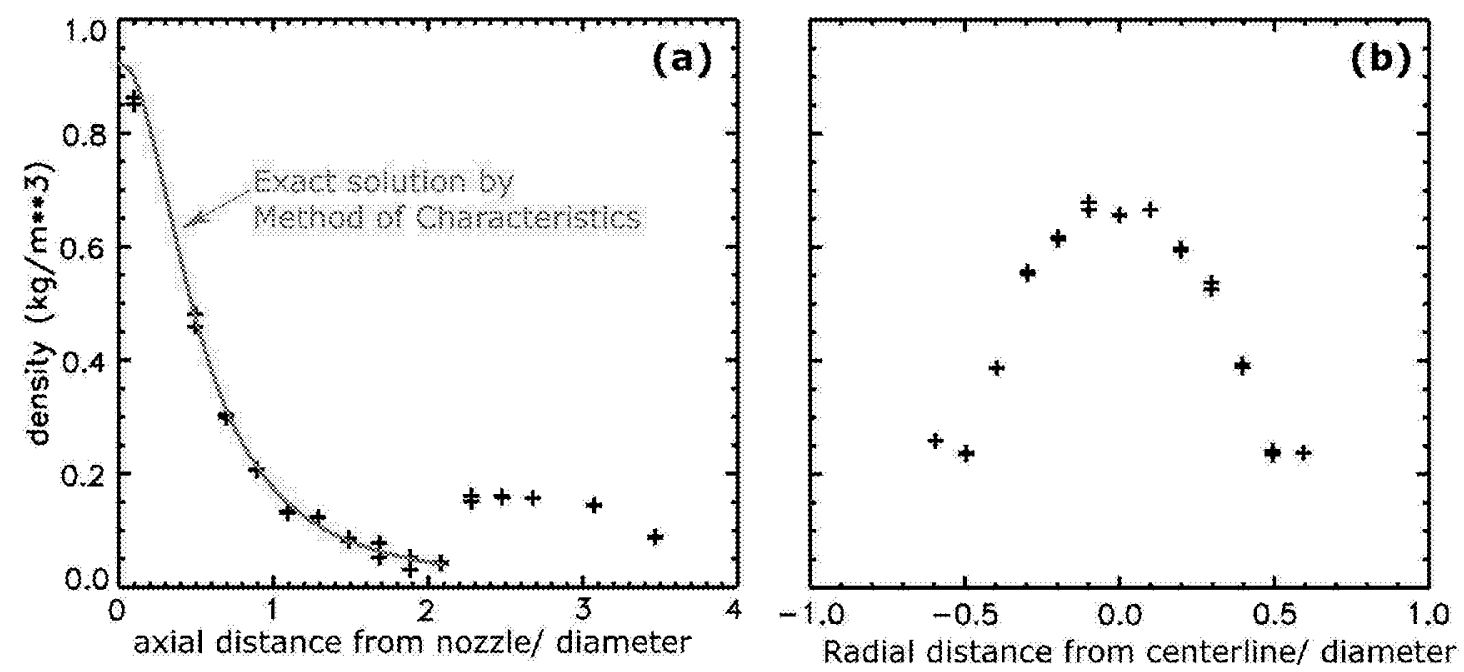

Figure 6. Density data from the plume of a cold, NPR 10, jet from a convergent nozzle. (a) Centerline variation: + experimental data, solid line-expected variation; (b) Radial profile at $\mathrm{x} / \mathrm{D}=0.3$.

\section{References}

1. Miles, R.B., Lempert, W.R., and Forkey, J.N., 2001, Laser Rayleigh scattering. Meas. Sci. Technol. 12, R33-R51.

2. Pitts, W.M., and Kashiwagi, T., 1984, The application of laser-induced Rayleigh scattering to the study of turbulence mixing. $J$. Fluid Mech., 141 391-429.

3. Forkey, J.N., Lempert, W.R., and Miles, R.B., 1998, Accuracy limits for planer measurements of flow field velocity, temperature and pressure using filtered Rayleigh scattering. Experiments in Fluids, 24, 151-162.

4. Elliott, G.S. and Samimy, M., 1996, Rayleigh scattering technique for simultaneous measurements of velocity and thermodynamic properties. AIAA J., 34 (11), 2346-2352.

5. Seasholtz, R.G., Zupanc, F.J., and Schneider, S.J., 1992, Spectrally resolved Rayleigh scattering diagnostic for hydrogen-oxygen rocket plume studies. J. Propulsion \& Power, 8(5), 935-942.

6. Panda, J., and Seasholtz, R.G. 1999 Velocity and Temperature Measurement in Supersonic Free Jets Using Spectrally Resolved Rayleigh Scattering. AIAA paper 99-0296.
7. Panda, J. and Seasholtz, R.G., 2002, Experimental investigation of density fluctuations in high-speed jets and correlation with generated noise, Journal of Fluid Mechanics, vol. 450, pp. 97-130.

8. Seasholtz, R.G., Panda, J., and Elam, K.A., 2002, Rayleigh scattering diagnostic for measurement of velocity and density fluctuation spectra, AIAA paper 2002-0827.

9. Beltran, L.R., Del Roso, R.L., and Del Rosario, R., 1992, Advanced Nozzle and Engine Component Test facility, NASA TM 103684.

10. Panda, J., and Seasholtz, R.G., 1999, Shock structure and shock-vortex interaction in screeching jets measured using Rayleigh scattering, Physics of Fluids, vol. 11, no. 12, 3761-3777.

11. Owen, P.L., and Thornhill, C.K., 1952, The flow in an axially-symmetric supersonic jet from a nearly-sonic orifice into a vacuum, Aeronautical Research Council Report \& Memoranda no. 2616.

12. Shapiro, A.H., 1953, The Dynamics and Thermodynamics of Compressible Fluid Flow, Vol. II, John Wiley \& Sons, pp. 676. 


\section{REPORT DOCUMENTATION PAGE}

Paperwork Reduction Project (0704-0188), Washington, DC 20503.

\begin{tabular}{|l|l|l|}
\hline 1. AGENCY USE ONLY (Leave blank) & $\begin{array}{c}\text { 2. REPORT DATE } \\
\text { November } 2002\end{array}$ & $\begin{array}{r}\text { 3. REPORT TYPE AND DATES COVERED } \\
\text { Technical Memorandum }\end{array}$ \\
\hline
\end{tabular}

\begin{tabular}{l|l} 
4. TITLE AND SUBTITLE & 5. FUNDING NUMBERS
\end{tabular}

Setting up a Rayleigh Scattering Based Flow Measuring System in a Large

Nozzle Testing Facility

6. AUTHOR(S)

WU-708-90-43-00

Jayanta Panda and Carlos R. Gomez

7. PERFORMING ORGANIZATION NAME(S) AND ADDRESS(ES)

National Aeronautics and Space Administration

John H. Glenn Research Center at Lewis Field

Cleveland, Ohio 44135-3191

8. PERFORMING ORGANIZATION

REPORT NUMBER

E-13655

9. SPONSORING/MONITORING AGENCY NAME(S) AND ADDRESS(ES)

10. SPONSORING/MONITORING

AGENCY REPORT NUMBER

National Aeronautics and Space Administration

Washington, DC 20546-0001

NASA TM-2002-211985

AIAA-2003-1089

\section{SUPPLEMENTARY NOTES}

Prepared for the 41st Aerospace Sciences Meeting and Exhibit sponsored by the American Institute of Aeronautics and Astronautics, Reno, Nevada, January 6-9, 2003. Jayanta Panda, Ohio Aerospace Institute, 22800 Cedar Point Road, Brook Park, Ohio 44142; Carlos R. Gomez, NASA Glenn Research Center. Responsible person, Jayanta Panda, organization code 5860, 216-433-8891.

12a. DISTRIBUTION/AVAILABILITY STATEMENT 12b. DISTRIBUTION CODE

Unclassified - Unlimited

Subject Category: 45

Distribution: Nonstandard

Available electronically at htp:/gitrs.grenasa.gov

This publication is available from the NASA Center for AeroSpace Information, 301-621-0390.

13. ABSTRACT (Maximum 200 words)

A molecular Rayleigh scattering based air density measurement system has been built in a large nozzle testing facility at NASA Glenn Research Center. The technique depends on the light scattering by gas molecules present in air; no artificial seeding is required. Light from a single mode, continuous wave laser was transmitted to the nozzle facility by optical fiber, and light scattered by gas molecules, at various points along the laser beam, is collected and measured by photon-counting electronics. By placing the laser beam and collection optics on synchronized traversing units, the point measurement technique is made effective for surveying density variation over a cross-section of the nozzle plume. Various difficulties associated with dust particles, stray light, high noise level and vibration are discussed. Finally, a limited amount of data from an underexpanded jet are presented and compared with expected variations to validate the technique.

\begin{tabular}{|c|c|c|c|}
\hline \multirow{2}{*}{\multicolumn{3}{|c|}{$\begin{array}{l}\text { 14. SUBJECT TERMS } \\
\text { Rayleigh scattering }\end{array}$}} & $\begin{array}{c}\text { 15. NUMBER OF PAGES } \\
15\end{array}$ \\
\hline & & & 16. PRICE CODE \\
\hline $\begin{array}{l}\text { 17. SECURITY CLASSIFICATION } \\
\text { OF REPORT } \\
\text { Unclassified }\end{array}$ & $\begin{array}{l}\text { 18. SECURITY CLASSIFICATION } \\
\text { OF THIS PAGE } \\
\text { Unclassified }\end{array}$ & $\begin{array}{l}\text { 19. SECURITY CLASSIFICATION } \\
\text { OF ABSTRACT } \\
\text { Unclassified }\end{array}$ & 20. LIMITATION OF ABSTRACT \\
\hline
\end{tabular}

